EARLY onset periodontitis (EOP) is a chronic inflammatory periodontal disease with a strong genetic link affecting individuals aged 17 to 25 . In the familial studies we tested the hypothesis about the role of Th 1 and Th 2 cytokines in the pathogenesis of EOP disease. The study involved 6 individuals with EOP disease and their 6 siblings with healthy periodontium. Actinobacillus actinomycetemcomitans (A. a.), a bacterium typical for EOP, was detected in all people studied. Th 1 and Th 2 cytokine production was measured after in vitro stimulation. Peripheral blood mononuclear cells (PBMC) were is olated and cultivated for $24 \mathrm{~h}$ and 7 days with PWM, A. a. or Escherichia coli. The levels of IL-4, IFN-gam ma, IgA, IgG and IgM were measured by ELISA methods. After in vitro stimulation of PBMC, a significantly higher production of IL-4 and significantly lower production of IFN-gamma were found in the group of patients compared with their healthy siblings. The increased level of $\mathrm{IL}-4$ in patients was in good agreement with an increased level of IgM after stimulation of lymphocytes with $E$. coli. These results support Seymour's hypothesis according to which patients with progressive disease primarily activate Th 2 lymphocytes while non-susceptible individuals activate Th 1 lymphocytes.

Key words: Early onset periodontitis, Th1, Th2, Cytokine profile, Immunoglobulin, Peripheral blood lymphocytes, Familial study, Actinobacillus actinomycetemcomitans, Escherichia coli

\section{Th1 and Th2 cytokine profile in patients with early onset periodontitis and their healthy siblings}

\author{
Jiřina Bártová ${ }^{1, C A}$, Zuzana Krátká-Opatrná', \\ Jarmila Procházková ${ }^{1}$, Otakar Krejsa ${ }^{1}$, \\ Jana Dušková', Lubor Mrklas' ${ }^{1}$, Helena Tlaskalováa \\ and Božena Cukrowská ${ }^{2}$
}

${ }^{1}$ Institute of Dental Research, Vinohradská 48, 12060 Prague 2, and ${ }^{2}$ Institute of Microbiology, Czech Academy of Sciences, Videňská 1083, 14000 Prague, Czech Republic ${ }^{2}$

${ }^{C A}$ Corresponding Author
Tel: +42224256718
Fax: +42224247034
Email: jirina.bartova@post.cz

\section{Introduction}

Early onset periodontitis (EOP) is a chronic inflammatory periodontal disease affecting individuals aged 17 to $25 .^{1}$ Pathological changes of the periodontal tissue are characterised by a mild resorption of alveolar bone and the presence of Actinobacillus actinomycetemcomitans (A. a.) in the gingival crevice area. Functional studies have de monstrated polymorphonuclear leukocytes (PMN) chemotactic defects in some $70 \%$ of subjects with EOP.

Periodontal disease is caused by bacteria in dental plaque, and evidence is accumulating that specific periodontal pathogens are associated with the progressive form of the disease.,2 However, some individuals harbour these specific bacteria but do not appear to show evidence of disease progression. Patient susceptibility is most likely genetically determined, although a number of local and environmental factors are thought to influence disease expression. ${ }^{3}$

Immunological mechanisms have been implicated in the pathogenesis of periodontal disease for over 30 years. In the 1970 s, attention focused on the participation of peripheral blood T lymphocytes in response to the action of dental plaque bacteria and on their role in the development of inflammation. ${ }^{4}$ Since then many papers have been published that concern the relationship between peripheral blood mononuclear cells (PBMC) blastic transformation and periodontitis..$^{5-7}$ The significance of the dental plaque bacteria on polyclonal B lymphocyte activation was really only studied later. ${ }^{7,8}$ Results showed that both specific and non-specific mechanisms of B lymphocyte activation can play a role in the pathogenesis of periodontal disease and that they can be highly influenced by the treatment. ${ }^{8-13}$ At the same time, immunological studies clearly established the B cell/plasma cell dominance of the periodontitis lesion. ${ }^{11,12}$

Both specific and non-specific activation are regulated by $\mathrm{T}$ lymphocytes. Based on the concept of functional Th $1 /$ Th 2 and Tc $1 /$ Tc 2 subsets, ${ }^{14,15}$ a model for the pathogenesis of periodontal disease has been constructed. ${ }^{16,17}$ According to the hypothesis of Seymour et al., ${ }^{16}$ patients with progressive disease activate mainly Th2 lymphocytes in response to an antigenic stimulus whereas patients with the slow type of the disease activate Th 1 lymphocytes. In the latter response it is proposed that a local expansion of the $B$ cell population would result, on the one hand, in the production of IL-1 and hence subsequent 
tissue destruction and, on the other hand, in the production of specific antibodies. It is further proposed that if protective antibody is produced it could result in the elimination of the organism and disease progression would cease. Production of antibody that is non-protective would, however, result in continuous connective tissue breakdown.

Our present study concerns the effect of short-term cultivation of peripheral blood lymphocytes with pokeweed mitogen (PWM), A. a. and Escherichia coli on the formation of IL- 4 and IFN-gamma in patients with early onset periodontitis and their healthy siblings. A. $a$. has been suggested to play a pathogenic role in the development of this disease. ${ }^{1}$ In our previous studies we have shown that polyclonal activation of B cells with a suspension of E. coli leads to high production of immunoglobulins by PBMC of patients with periodontitis. ${ }^{18}$ The results should contribute to finding the origins of the susceptibility to early onset periodontitis.

\section{Materials and methods}

Tw o years before beginning this study the group of 47 patients with EOP was collected from a set of 9225 young (16-19 years) individuals at the Institute of Dental Research. These patients met the basic clinical diagnosis criterion of periodontitis: they had at least one periodontal pocket deeper than $3 \mathrm{~mm}$, situated in the region of the molars or incisors, inflammation of gingiva and the presence of the suspect pathogenthe bacterium $A$. a.-in the sulcular region. There were no individuals with systemic disease or pregnant women in the group of patients.

During the familial study ${ }^{19}$ we found that among the total of 47 patients and their 54 siblings only 6 patients had siblings with healthy periodontium and presence of $A$. a. in sulcular region. These families were included in this study.

In agreement with Helsinki conventions (1964), informed consent for blood collection for immunological examination was obtained from all persons examined.

\section{Clinical examination}

The examination of patients at the beginning of therapy included the determination of gingival inflammation using the gingival index (GI), ${ }^{20}$ ascertaining the depth of the pockets with the calibrated probe and X-ray. This was followed immediately by conservative treatment. The dental calculus was removed, unsatisfactory fillings or crowns were restored and correct tooth brushing technique was demonstrated. All patients were thoroughly instructed in oral hygiene including teeth cleaning and gingival massage. They were also warned that oral hygiene is the decisive factor in periodontitis therapy. The con- servative part of the therapy lasted 4 weeks and was followed by a 10-day tetracycline treatment. Two weeks after the antibiotic therapy the patients were invited for a control clinical examination, with further check-ups at 3-and then 6-month intervals.

This study reports on the results of an immunological examination 2 years after the start of the therapy.

\section{Bacterial suspension and mitogens}

A. $a$. was isolated from a subgingival locality from the patients of the experimental group. Bacterial culture was incubated for $48 \mathrm{~h}$ in Brain Heart Infusion (Oxoid) medium and then inactivated for $20 \mathrm{~min}$ at $120^{\circ} \mathrm{C}$. The bacterial suspension was washed 4 times with physiological saline, centrifuged at $600 \mathrm{~g}$ and adjusted to the required concentration $\left(10^{9}\right.$ cells $\left./ \mathrm{ml}\right)$ with RPMI 1640 tissue culture medium.

The suspension of heat-killed bacteria of the E. coli 086 strain was obtained from the Department of Immunology, Institute of Microbiology, Academy of Sciences of the Czech Republic, and diluted to the experimentally optimal concentration $\left(10^{9} \mathrm{cells} / \mathrm{ml}\right)$ with RPMI medium.

PWM (Phytolacca americana mitogen, Sigma) and ConA (Concanavalin A, Sigma) were diluted to the ex perimentally optimal concentration (PWM $2 \mu \mathrm{g} / \mathrm{ml}$, PWM $2 \mu \mathrm{g} / \mathrm{ml}+$ ConA $10 \mu \mathrm{g} / \mathrm{ml}$ ) with RPMI 1640 tissue culture medium.

\section{Stimulation of lymphocytes to cytokine and immunoglobulin production}

Mononuclear cells isolated from the peripheral blood of the patients and their siblings with healthy periodontium were washed, diluted with a supplemented tissue culture medium RPMI 1640 to a concentration of $10^{6} / \mathrm{ml}$, and cultivated with mitogens and heat-killed bacteria $\left(\right.$ A. a. $10^{8} / \mathrm{ml}$ and E. coli $10^{8} / \mathrm{ml}$ ), as described earlier. ${ }^{21}$ Supernatants were taken after $24 \mathrm{~h}$ and after 7 days, which were then stored at $-20^{\circ} \mathrm{C}$ until further assay.

\section{Assay of cytokines and immunoglobulins in culture media}

Cytokine assay.

Cytokines IL-4 and IFN-gamma were assayed in the tissue culture supernatants using commercial Immunotech France kits. The technique is based on the sandwich method in which monoclonal antibody is used as a binding antibody, and another biotinylated monoclonal antibody is used for detection. This second antibody reacts with the streptavidin-peroxidase conjugate. The binding enzymatic activity is determined by adding a chromogen (without TMB), and the colour intensity is measured on an SLT Spectra II microreader. 
Enzyme linked immunosorbent assay of

immunoglobulins ELISA assay of

immunoglobulins.

Polyclonal antibodies Q-SwaHu-IgM, Q-SwaHu-IgG or Q-SwaHu-IgA (Sevac, Prague) were used as the binding antibodies. After incubation and washings, control sera with defined immunoglobulin contents and the supernatants were applied. Following incubation and washing, peroxidase-labelled antibodies against human immunoglobulin (Q-SwaHu-IgM, Q-SwaHu-IgG or Q-SwaHu-IgA) were added. A 1-h incubation at room temperature was followed by washing the plates and the redox reaction with OPD in phosphate ELISA buffer $(\mathrm{pH}=6.2)$ was developed using hydrogen peroxide. The reaction was stopped with $1 \mathrm{M}$ sulphuric acid and read on an SLT Spectra II ELISA reader. Individual samples were evaluated in $\mathrm{ng} / \mathrm{ml}$ using the KIME E program.

\section{Statistical evaluation}

Student's pair $t$-test at a probability level of $P=0.05$ was used to evaluate the significance of differences between patients and their siblings. The results are presented as mean $\pm \mathrm{SE}$.

\section{Results}

Cytokine production by PBMC after a 24-h stimulation by mitogen and bacteria suspensions is shown in Table 1. The IFN-gamma formation was found to be significantly higher in healthy siblings than in the patients after stimulation by $A$. $a$. and E. coli. On the other hand, a significantly higher formation of IL-4 was detected in patients after stimulation by $A$. $a$. and E. coli as compared with their healthy siblings.

The release of immunoglobulins after a 7-day stimulation of PBMC by mitogen and bacteria suspensions is show $\mathrm{n}$ in Table 2. Compared to their siblings, patients exhibited a significantly higher IgM level after polyclonal stimulation with $E$. coli. The formation of IgA was significantly higher in the patients than in their siblings in cultures stimulated by both PWM and ConA. No significant differences were found after stimulation of PBMC by other mitogens and in unstimulated cultures. No significant differences were found in the level of IgG.

\section{Discussion}

Evidence based on microbiological, immunological and animal studies has shown that some forms of periodontal disease in adults can remain stable over many years and not endanger the life of the dentition, whereas other forms, despite extensive treatment, continue to break down, leading ultimately to tooth loss. $^{22}$

The regulatory activity of $\mathrm{T}$ lymphocytes and the identification of which cytokines are present have been studied intensively in order to shed some light on the pathogenesis of periodontal disease. It has been show $n$ that individuals susceptible to periodontal disease predominantly activate Th2 lymphocytes, while non-susceptible individuals activate Th1 lymphocytes. ${ }^{16}$

The verification of this hypothesis required a correct selection of patients. Patients with early onset periodontitis (susceptible individuals) and their siblings with healthy periodontium (non-susceptible individuals), both exhibiting presence of $A$. a., seem to be ideal for the study of the role of Th1 and Th2 lymphocytes in the pathogenesis of the disease. Despite the similar genetic backgrounds, similar age and similar hygiene habits in families, we found different production of cytokines after in vitro stimulation.

The majority of immune responses occur locally rather than systemically within a small area of tissue: therefore most authors have concentrated on the $T$ cells isolated from inflamed tissues of patients. ${ }^{16,23-26}$ This tissue can be obtained during surgical treatment of seriously affected patients. Lymphocytes isolated from peripheral blood of patients are rarely used. ${ }^{27-29}$ The use of PBMC is favourable for analysing the transformation of the immune response during the disease's remission, when it is not possible to use cells from the tissue.

PBMC were capable of expressing mRNA for IL-2, IL-4, IL-5, IL-6, IL-10, IL-13 and IFN-gamma

Table 1.+Release of IFN-gamma and IL-4 after the stimulation (24 h) of PBMC by mitogens and antigens ${ }^{\mathrm{a}}$

\begin{tabular}{|c|c|c|c|c|c|c|}
\hline \multirow[t]{2}{*}{ Mitogens and activators } & \multicolumn{3}{|c|}{ IFN-gamma $(\mathrm{U} / \mathrm{ml} \times 1000)$} & \multicolumn{3}{|c|}{$\mathrm{IL}-4(\mathrm{ng} / \mathrm{ml})$} \\
\hline & Patients & Siblings & Significance & Patients & Siblings & Significance \\
\hline $\begin{array}{l}\text { PWM } \\
\text { PWM+ConA } \\
\text { A. a. } \\
\text { E. coli } \\
\text { Unstimulated }\end{array}$ & $\begin{aligned} 30 & \pm 12 \\
34 & \pm 11 \\
6 & \pm 2 \\
4 & \pm 1 \\
740 & \pm 734\end{aligned}$ & $\begin{aligned} 28 & \pm 12 \\
861 & \pm 824 \\
178 & \pm 14 \\
125 & \pm 10 \\
54 & \pm 4\end{aligned}$ & $\begin{array}{l}P<0.05 \\
P<0.05\end{array}$ & $\begin{aligned} 92 & \pm 40 \\
175 & \pm 62 \\
394 & \pm 216 \\
149 & \pm 51 \\
50 & \pm 26\end{aligned}$ & $\begin{array}{r}136 \pm 65 \\
104 \pm 45 \\
55 \pm 22 \\
35 \pm 19 \\
52 \pm 22\end{array}$ & $\begin{array}{l}P<0.05 \\
P<0.05\end{array}$ \\
\hline
\end{tabular}

a Student's pair $t$-test at a probability level of $P=0.05$ was used to evaluate the significance of differences between patients and their siblings. The results are presented as mean $\pm \mathrm{SE}$. 


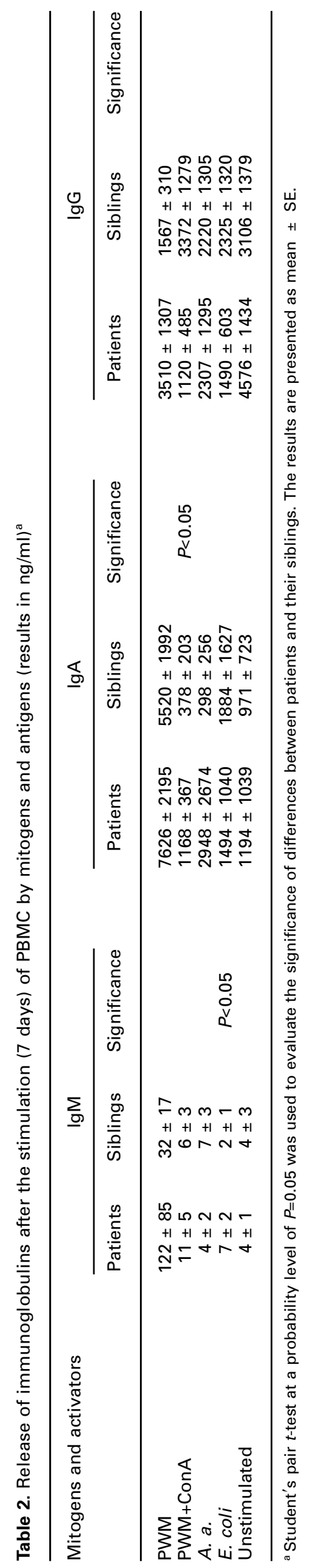


following stimulation by ConA for $2 \mathrm{~h}^{29}$ Cells isolated from affected tissue only expressed IL-10, IL6, IL-13 and IFN-gamma. It seems that PBMC were capable of producing a whole spectrum of cytokines, but after homing of $\mathrm{T}$ cells into inflamed tissue, they were only capable of expressing either Th1 or Th2 cytokines.

By immunohistochemical analysis a higher percentage of IL- 4 and IL- 6 producing cells was found in the tissues affected by inflammation. ${ }^{23}$ Following in vitro stimulation by Porphyromonas gingivalis and Fusobacterium nucleatum, most lymphocytes obtained from biopsies of periodontitis affected tissues were of the Th2 phenotype, i.e. they formed high amounts of Il- 4 and only small amounts of IL-2 and IFN-gamma. ${ }^{16}$ Manhart $e$ t al. ${ }^{24}$ proved that altered IL-2/IL-4 activities were founded in lesion of patients with early onset periodontitis.

After activation by PHA, CD8+CD28+ cells isolated from inflamed lesions of patients with adult periodontitis ${ }^{25,26}$ produced high amounts of IFN-gamma and were shown to have cytotoxic activity, whereas $\mathrm{CD} 8+\mathrm{CD} 28$-cells produced predominantly IL -4 and IL-5 and they showed a suppressive effect.

We found a significantly higher formation of IL-4 and significantly lower formation of IFN-gamma after E. coli stimulation in patients with EOP as compared with their siblings. These results corroborate the finding of a significantly higher count of PBMC that produce IL-4 after $P$. gingivalis and Lipopolysaccharide (LPS) stimulation, which was detected by Aoyagi et al. ${ }^{30}$ in patients $w$ ith adult periodontitis.

As a B cell growth factor, IL-4 stimulates the prolife ration and differentiation of $B$ lymphocytes and induces the expression of MHCII class II antigens on $\mathrm{B}$ lymphocytes. It also stimulates the antigen-specific antibody response, which has a protective character and will probably be activated in patients in the resting stage. ${ }^{16,31}$ On the other hand, polyclonal activation probably leads to the progression of the disease.

A higher production of imunoglobulins after the polyclonal stimulation of B lymphocytes was found in patients compared with their siblings. Compared to their siblings, patients exhibited a significantly higher IgMlevel after polyclonal stimulation with $E$. coli. The formation of $\operatorname{IgA}$ was significantly higher in the patients than in their siblings in cultures co-stimulated by PWM and ConA.

Prediction of clinical disease activity in patients is not yet possible, and only the measurement of past activity is currently available. The establishment of a means for classifying patients as susceptible or nonsusceptible is therefore necessary to define patient selection more precisely. ${ }^{31}$ The pathogenic mechanisms involved in the development of EOP have yet to be elucidated, but the prevalent production of IL-4 by the patients' peripheral blood lymphocytes suggests that Th2 cells, and probably B cells, and their products may play an important role in the pathogenesis of this disease.

ACKNOWLEDGEMENTS. This study was supported by grant $5006-3$ of the Czech Ministry of Health.

\section{References}

1. Rateitschak KH, Rateitschak EM, Wolf HF, Hessl TM. Periodontology. Stuttgart: Thieme, 1998

2. Jordan HV, Keys PH. Aerobic gram-positive filamentous bacteria as ethiologic agents of experimental disease in hamsters. Arch Oral Biol 1964: 9:401-14

3. Seymour GJ. Importance of the host response in the periodontium. $J$ Clin Periodontol 1991: 18:421-6

4. Ivanyi L, Lehner T. Stimulation of lymphocyte transformation by bacterial antigens in patients with periodontal disease. Arch Oral Biol 1970: 15:1089-96

5. Ivanyi L, Lehner T. Lymphocyte transformation by sonicates of dental plaque in human periodontal disease. Arch Oral Biol 1971: 15:1117-21

6. Mackler BF, Altman LC, Rosenstreich DL, Oppenheim JJ. Human B lymphocyte activation: induction of lymphokine production by EAC and blastogenesis by soluble mitogens. Nature 1974: 449:834-6

7. Mackler BF, Altman LC, Wahl SM, Rosenstreich DL, Oppenheim JJ, Margenhagen SE. Blastogenesis and lymphokine synthesis by $T$ and $B$ lymphocytes from patients with periodontal disease. Infect Immun 1974: 10:844-50

8. Donaldson SL, Ranney RR, Burgmeister JA, Tew JG. Blastogenic responses by lymphocytes from periodontally healthy populations induced by periodontitis associated bacteria. J Periodontol 1982: 53:743-51

9. Page RC, Schroeder HE. Pathogenesis of inflammatory periodontal disease. A summary of current work. Lab Invest 1976: 34:235-49

10. Mackler BF, Frostad KB, Robertson PB, Levy BM. Immunoglobulin bearing lymphocytes and plasma cells in human periodontal disease. $J$ Periodontol Res 1977: 12:37-45

11. Seymour GJ, Powell RN, Davies WIR. Conversion of a stable T-cell to a progressive B-cell lesion in the pathogenesis of chronicle inflammatory periodontal disease. J Clin Periodont 1979: 6:267-77

12. Okada H, Kida T, Yamagami H. Identification and distribution of immunocompetent cells in inflamed gingiva of human chronic periodontitis. Infect Immun 1983: 41:365-74

13. Tew JG. Periodontal disease: humoral immune mechanisms including specific and polyclonal. Clinical Immunol Newsletter 1988: 9:188-90

14. Mosmann TR, Coffman RL. Th1 and Th2 cells: different patterns of lymphokine secretion lead to different functional properties. Ann Rev Immunol 1989: 7:145-73

15. Bloom BR, Salgame P, Diamond B. Revisiting and revising suppressor T cells. Im munol To day 1992: 1:131-6

16. Seymour GJ, Gemmell E, Reinhardt RA, Eastcott J, Taubman MA. Immunopathogenesis of chronic inflammatory periodontal disease: cellular and molecular mechanisms. J Periodont Res 1993: 28:478-86

17. Seymour GJ, Gemmell E, Westerman B, Cullinan M. Periodontics in to the 21st century. Adv Exp Med Biol 1996: 409:359-63

18. Bártová J, Tlaskalová-Hogenová $\mathrm{H}$, Mrklas L et al. Immunomodulating effects of bacterial antigens: polyclonal and specific in vitro activation of B lymphocytes from healthy donors and patients with periodontal disease. In: Rýc M, Franek J, eds Bacteria and Host. Prague: Avicenum, 1986: 373-6

19. Procházková J, Bártová J, Krejsa O, Smausová R, Dušková R, Mrklas L. Changes in neutrophil function in patients w ith early onset periodontitis according to family occurrence of the disease. In: Mestecky J et al. Advances in Mucosal Immunology. New York: Plenum Press, 1995: 1127-9

20. Loe H, Theilade E, Jensen HB. Experimental gingivitis in man. J Periodontol 1965: 36:177-87

21. Tlaskalová-Hogenová H, Bártová J, Mrklas Let al. Stimulation of human blood lymphocytes by different polyclonal B cell activators of bacterial and plant origin: production of $\operatorname{IgM}, \operatorname{IgG}$ and $\operatorname{Ig}$ A estimated by ELISA method. Folia Microbiol 1985: 30:258-66

22. Seymour GJ. Possible mechanisms involved in the immunoregulation of chronic inflammatory periodontal disease. J Dent Res 1987: 66:2-9

23. Yamazaki K, Nakajima T, Hara K. Immunohistological analysis of T cell functional subse ts in chronic inflammatory periodontal disease. Clin Exp Immunol 1995: 99:384-91

24. Manhart SS, Reinhardt RA, Payne JB, Seymour GJ, Gemmell E, Dyer JK, Petro TM. Gingival cell Il-2 and Il-4 in early onset periodontitis. J Periodontol 1994, 65:807-13

25. Wassenaar A, Reinharddus C, Abraham-Inpijn L et al. Type-1 and type-2 CD8+ T-cell subsets isolated from chronic adult periodontitis tissue differ in surface phenotype and biological function. Immunol 1996: 87:113-8 
26. Wassenaar A, Reinhardus C, Thepen T, Abraham-Inpijn L, Kievits F Cloning, characterisation, and antigen specificity of Tlymphocyte subsets extracted from gingival tissue of chronic adult periodontitis patients. Infect Imm un 1995: 63:2147-53

27. Engel D, Montingho S, Rabinowitch P, Clagett J, Stone R. Mitogen induced hyperproliferation response of peripheral blood mononuclear cells from patients with severe generalised periodontitis: lack of correlation with proportions of T cells and T-cell subjects. Clin Immunol Immunopath 1984: 30:374-8

28. Kono Y, Beagley KW, Fujihashi K. Cytokine regulation of localised infammation. Induction of activated B cells and IL-6-mediated polyclonal IgG and IgA synthesis in inflamed human gingiva. J Immunol 1991: 46:1812-21

29. Fujihashi K, Yamamoto M, Hiroi T, Bamberg TV, McGhee JR, Kiyono H Selected Th1 and Th2 cytokine mRNA expression by CD4+ T cells isolated from inflamed human gingival tissues. Clin Exp Im m unol 1996 103:422-8

30. Aoyagi T, Sugawara-Aoyagi M, Yamazaki K, Hara K. Interleukin 4 (IL-4) and IL-6 producing memory T-cells in peripheral blood and gingival tissues in periodontitis patients with high serum antibody titers to Porphyromonas gingivalis. Oral Microbiol Immunol 1995 10:304-10

31. Gemmel E, Marshall RI, Seymour GJ. Cytokines and prostaglandins in immune homeostasis and tissue destruction in periodontal disease. Periodontol 1997: 14:112-43

\section{Received 27 March 2000;}

accepted 31 March 2000 


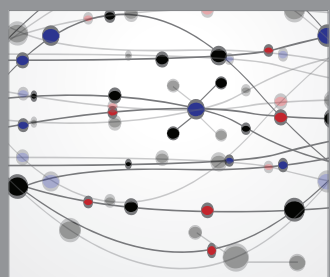

The Scientific World Journal
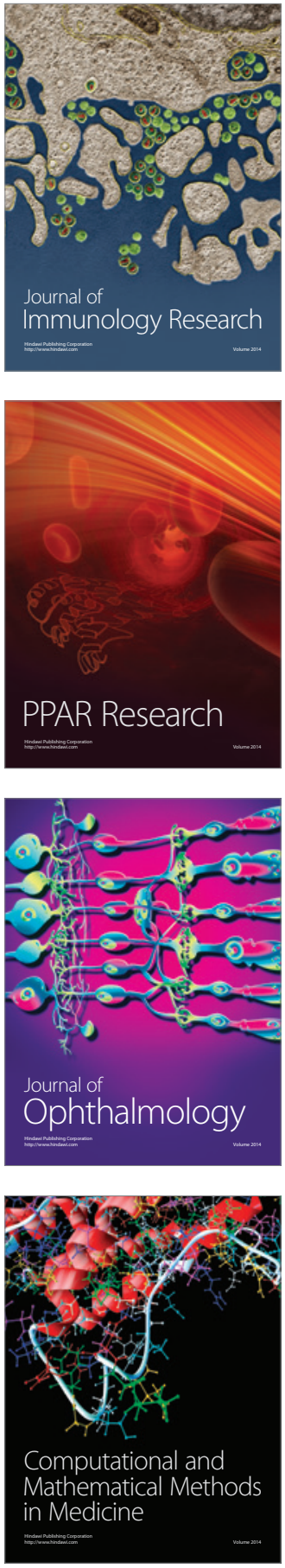

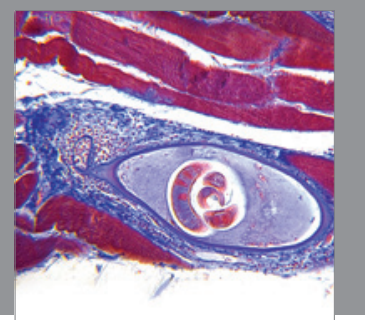

Gastroenterology

Research and Practice
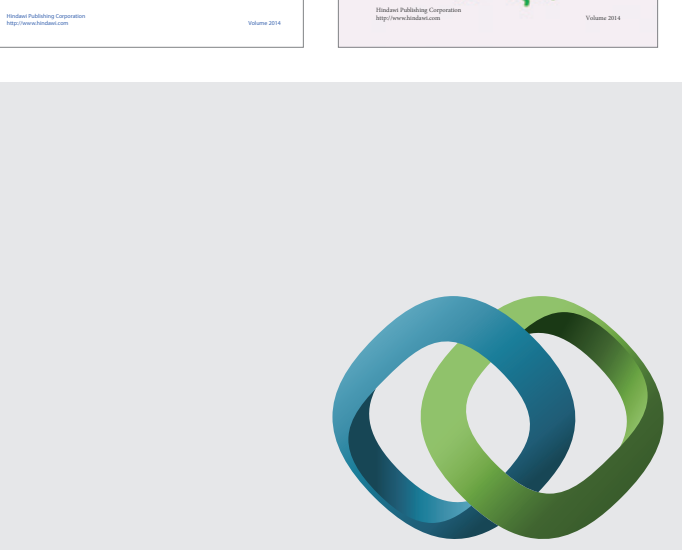

\section{Hindawi}

Submit your manuscripts at

http://www.hindawi.com
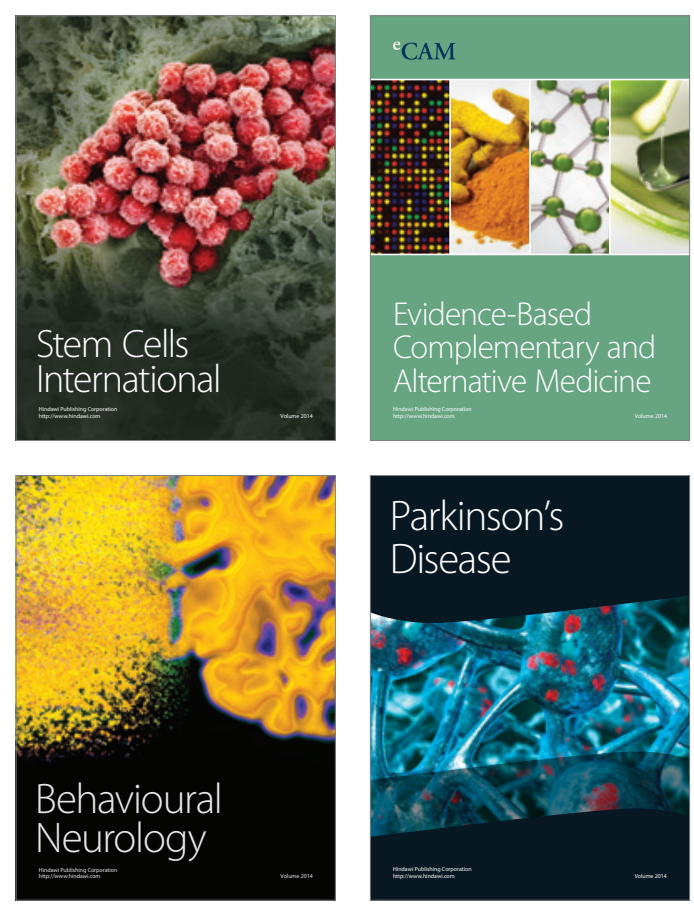

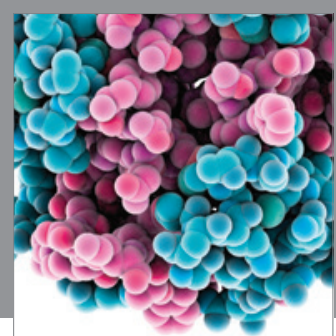

Journal of
Diabetes Research

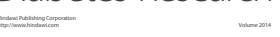

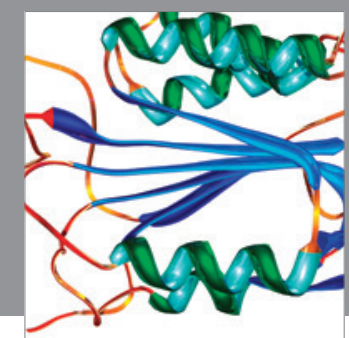

Disease Markers
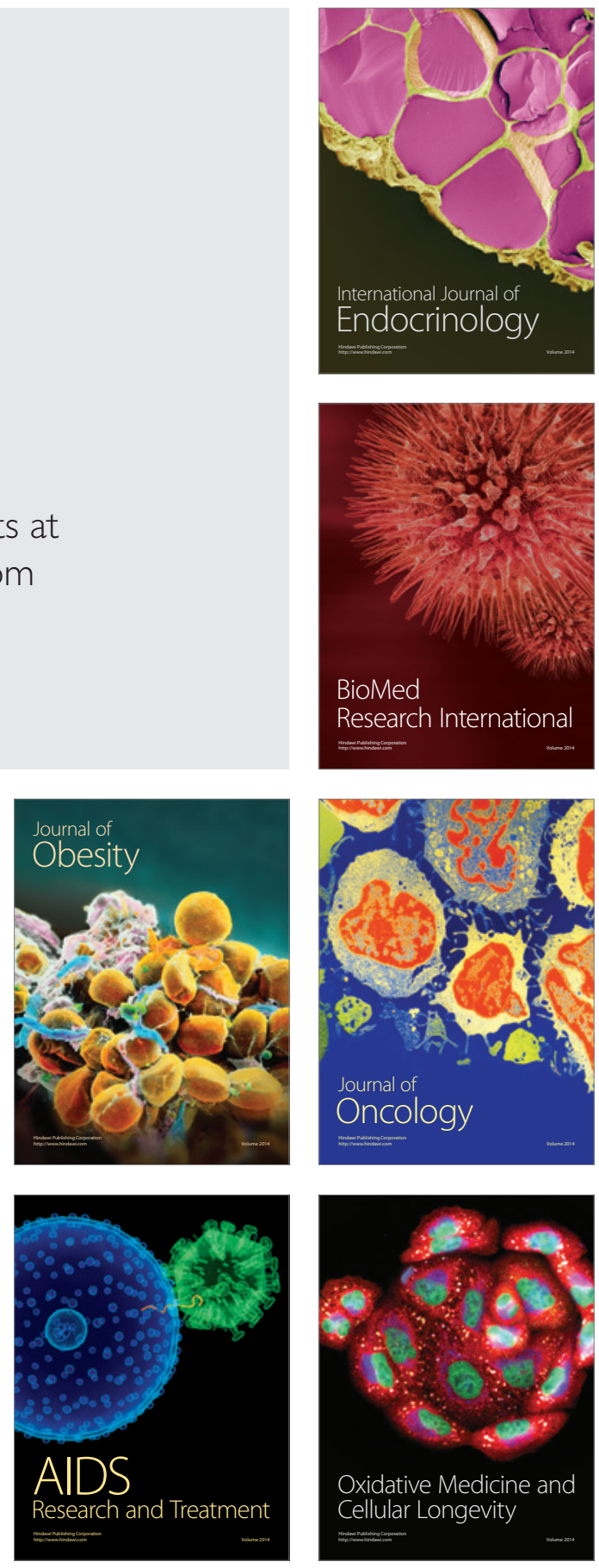